\title{
Walking The Walk: How The Theory Of Reasoned Action Explains Adult And Student Intentions To Go Green
}

\author{
Linda Jane Coleman, Salem State University, USA \\ Nisreen Bahnan, Salem State University, USA \\ Mayuresh Kelkar, Salem State University, USA \\ Nicole Curry, Salem State University, USA
}

\begin{abstract}
This research paper applies the Theory of Reasoned Action (TRA) to the growing trend of consumers going green. The study includes a survey informed by the TRA to show how attitudes and beliefs influence intention and behavior. The survey was administered to two samples consisting of 202 adult non-student participants and 302 undergraduate business students in the northeastern United States. The findings indicate differences in green and non-green consumer behavior between the student and adult respondents. The findings support the hypothesis that green consumption intentions affect actual green consumption behavior. The findings show how nuances occur between measures of attitudes, subjective norms, and intention. The article concludes with insights for planning effective policy and firm-level marketing strategies to encourage consumer-green thinking, feeling, and acting.
\end{abstract}

Keywords: green consumerism; theory of reasoned action; green marketing; corporate social responsibility; consumer attitudes; consumer behavior

\section{INTRODUCTION}

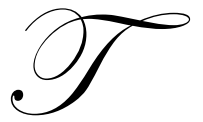

oday, the business philosophies of "going green" and being "eco-friendly" are popular and firms are creating marketing programs that focus on responding favorably to applying such views. This stance was not always the case. Although environmental consumption became a subject of study in the late 1960 's, the actual term, "green marketing," did not come into prominence until the late 80's and throughout the 90's, a time period that also saw a rise in eco-labeling (D'Souza, Tagian, Lamb, \& Peretiatk, 2007; Horne, 2009).

The concept of becoming environmentally conscious has transformed from an afterthought to a top priority for many firms (Mintzer, 2008). Now, almost every industry bears witness to green marketing initiatives as achievements in radical innovation. Green is the new "new and improved" (Wilson, 2007). As eminent New York Times columnist Thomas Friedman (2008) purports, green is the new red, white, and blue in America.

\section{Purpose of the Study}

The present study investigates why consumers engage or do not engage in green consumption behavior. The Theory of Reasoned Action (TRA) posits that intentions must precede consumer behavior (Fishbein \& Ajzen, 1975). Intentions are in turn determined by consumer attitudes and social subjective norms. First, the history of the green consumption movement over the past few decades will be reviewed. Next, the TRA is briefly reviewed and applied to predict green consumption behavior. The subsequent section describes the data collection procedure and reviews the key findings of the data analysis. The paper concludes by delineating the managerial implications of the results of this research. 


\section{Focus of the Study}

Recent climate changes have sparked an interest among green and non-traditionally green consumers to seek and demand sustainable products (Horne, 2009; Straughan \& Roberts, 1999). Discussions about identifying the ecologically concerned consumers date back to over forty years ago. A study from the early seventies empirically explores the relationship between the socioeconomic and personality characteristics of consumers and the amount of, if any, ecological concern they indicated (Kinnear, Taylor, \& Ahmed, 1974). This established that the ecologically concerned segment may be large enough to warrant exploitation (Kinnear, Taylor, \& Ahmed, 1974). This study advances theory and research by, examining how attitudes and social norms of the consumer affect adult and student intentions to go green.

Green consumption can have different meanings for different people. For some this means recycling, energy conservation, energy efficient appliances, mass transit or car-pooling. Others are compelled to act in other ways such as getting involved in their communities regarding hazardous waste sites, proper disposal of certain products and toxic chemicals, or answering a call to work with grass-roots efforts and legislation. The major question surrounding green marketing is what is getting consumers interested and what is getting them to act on these interests.

\section{Conceptual and Theoretical Framework}

Substantial research looks at why people behave in certain ways and what can be done to change behavior. Landmark research in this area was conducted by Fishbein and Ajzen (1975) with their presentation of the Theory of Reasoned Action (TRA). The TRA is a general theory of human behavior that examines the relations among beliefs, attitudes, intentions, and behaviors (Ajzen \& Fishbein, 1980; Fishbein, 1967; Fishbein, 1980; Fishbein \& Ajzen, 1975). In their theory, intention influences behavior. The factors contributing to intention include attitude and subjective norms (Chatzidakis, Hibbert, \& Smith, 2007; Fishbein, Middlestadt, \& Hitchcock, 1991). Research using the TRA may help identify the antecedents of behavior and predict what someone will or will not do so that interventions can be developed that will ultimately change behavior. Interventions are not designed just to change behavior, they are designed to change beliefs which will in turn change behavior (Fishbein, Middlestadt, \& Hitchcock, 1991).

The TRA may be useful empirically in identifying the factors underlying green behavior. The theory has been used in the social psychology and marketing literature to explain why people choose to engage in a variety of behaviors such as smoking, drinking, and sexual transmissible diseases-related behavior (Ajzen, 1991; Chassin, Presson, Bensenburg, Corty, Olshavsky, \& Sherman, 1981; Schlegel, Crawford, \& Sanborn, 1977).

Attitude towards behavior $\left(A_{b}\right)$ is a person's positive or negative feeling associating with performing a specific behavior. According to the TRA, $A_{b}$ is a function of the individual's belief (the cognitive component) that performing a given behavior will result in certain outcomes, coupled with that individual's evaluation (the affective component) of these outcomes. In other words, a person will hold a favorable attitude towards a given behavior if $\mathrm{s} / \mathrm{he}$ believes that performing this behavior will lead to mostly positive outcomes. On the other hand, if the individual believes that the behavior will lead to mostly negative outcomes, then s/he will form an unfavorable attitude towards that behavior.

Subjective norms(SN) are a function of the individual's beliefs that referent others (influential individuals or groups) think s/he should or should not engage in this given behavior coupled by the individual's willingness or motivation to comply with these referent others.

Intention is the likelihood that a person will engage in a specific behavior. Intention is the best predictor of behavior, and hence, to change a specific behavior, one must first change the intention to perform that behavior. According to the TRA both attitude towards behavior $\left(\mathrm{A}_{\mathrm{b}}\right)$ and subjective norms $(\mathrm{SN})$ impact the intention to perform the behavior. Behavior is the transition of intention into overt action. Several studies apply the TRA to consumer behavior as it pertains to breast feeding, intention to seek cancer information, and faculty attitudes towards teaching online courses, use of technology and text messaging, to name a few examples (Ceccucci, Peslak, 
\& Sendall, 2010; Chen \& Chen, 2006; Garman, Arnett, \& Mauk, 2008; Ross, Kohler, Grimely, \& Anderson-Lewis, 2007). This paper contributes to the literature by testing the predictive power of the TRA to predict green consumption behavior (Figure 1 available from authors).

One of the limitations of this theory lies in the self-reporting technique used to learn respondents' attitudes and subjective norms. Self-reported data tends to be highly subjective and less valid. Another limitation stems from the assumption that all behavior is voluntary and consciously analyzed beforehand. This theory fails to predict or explain irrational or impulsive behaviors. Some studies findings show that behavioral intention does not always lead to actual behavior when an individual's control over the behavior is incomplete. To address this issue, Ajzen (1991) propose the Theory of Planned Behavior (TPB), which extends the TRA by adding the perceived behavioral control component to account for behaviors that occur without a person's volitional control. Sheu (2006) explored whether TRA or TPB better predicts students' behavioral intentions. The study's results reveal that TPB outperforms TRA in predicting favorable behavioral intentions (FBIs), and TRA and TPB show equal abilities in predicting unfavorable behavioral intentions (UFBIs). Furthermore, results demonstrate that attitude has a more significant effect than subjective norms and perceived behavior control in predicting both FBIs and UFBIs.

\section{Theoretical Contribution}

TRA receives wide support in recent literature. Golan and Banning's (2008) found that subjective norms can motivate a person to take socially desirable action. Chan (2001) concluded that, consistent with the TRA, green purchase is a significant predictor of green purchase behavior. Shaharudin, Pani, Mansor, and Elias (2010) also used TRA in predicting the consumer purchase intention of organic foods usage among Malaysian consumers. Fishbein's (2008) "A Reasoned Action Approach to Health Promotion", describes the integrative model of behavioral prediction (IM), which attempts to identify a limited set of variables that may account for the variance in a given behavior. The IM is consistent with the original TRA since it assumes that intentions are a function of attitudes and subjective norm, and they are the immediate antecedents of behavior. It, however, extends TRA to recognize that environmental factors, skills and abilities can moderate the intention-behavior relationship. The present study focuses on the use of the TRA in the field of green marketing

\section{LITERATURE REVIEW}

As mentioned earlier, green marketing is now a top priority for businesses. People are exposed to green marketing more now than they were twenty years ago and this is contributing to an increase in awareness. Environmental issues are also gaining public awareness through the media, with an example being Al Gore's film, "An Inconvenient Truth", which looks at the effects of greenhouse gases and the lack of energy conservation in the United States (Brandt, 2007). Studies suggest that consumers who know more about environmental issues are more likely to purchase green products. With all the confusion surrounding green marketing, the difficulty in identifying green consumers comes as no surprise, as this segment continues to constitute a population about which little is known (D’Souza, Taghian, \& Kholsa, 2007).

Despite the growing popularity of green marketing, not everyone believes in it. Some feel that consumers are more interested in factors like price, functionality, and packaging than if a product is green or not, meaning that green marketing does not really affect consumer purchasing intent (Pfanner, 2007). This may sound confusing since green marketing has become such a major issue, but a gap exists between what people see as a problem and what they are willing to do in response (Prescott \& Taylor, 2008).

Several studies explore consumer characteristics, beliefs, and attitudes, in relation to green marketing responses (Friedman, 2008). In a landmark comprehensive study, Tanner and Kast (2003) investigated the impact of attitudes, socioeconomic factors and situational factors in Swiss consumers' decision to consume green food products. They discovered that attitudes towards environmental protections rather than socioeconomic status were the key in predicting who would go green. In a similar study, Chan (2001) showed that consumers from collectivist and nature oriented cultures, such as the Chinese, are more likely to go green. The findings of studies examining education and environmental issues are more consistent than other traditionally used demographic variables such as age, gender, and income. However, a definitive relationship between the two variables of education and 
environmental issues has yet to be established. The vast majority of the studies report this predicted positive relationship. Other studies find the opposite, citing that education is negatively correlated with environmental attitudes. Kinnear et. al. (1974) finds no significant relationship between the two.

Place of residence is another variable of interest since the early days of green research, with growing importance in the later 1900's. Of the many studies that address place of residence as a correlate of green attitudes and behaviors, all but one, Hounshell and Liggett (1973), found that those living in urban areas are likely to show more favorable attitudes towards environmental issues, but the relationship is not significant.

Hine and Gifford (1991) identify psychographic correlates of green attitudes and behaviors. This study provides interesting insights into the nature of the green consumer. Hine and Gifford (1991) investigate the effect of a fear appeal relating to the anti-pollution movement on several different pro-environmental behaviors. They find that a significant correlation exists among individuals with more liberal political beliefs being more likely to exhibit strong verbal commitment than those with more conservative political views. Roberts (1996) further confirms this liberalism effect. His study, however, establishes liberalism as relevant across a general range of ecologically conscious concerns and behaviors rather than focusing on any single concern.

\section{HYPOTHESIS}

The relationship between attitudes and behavior is one that has been explored in a variety of contexts. In the green consumption literature, the question has been addressed by exploring the relationship between the attitudinal construct, environmental concern, and various behavioral measures and/or observations. The studies examining environmental concern as a correlate of environmentally friendly behavior report a positive correlation between the two (Straughan \& Roberts, 1999).

Overall, beliefs and attitudes do not always translate into behavior. The correlation between beliefs, attitudes, and behavior is a complicated subject. Beliefs and attitudes do affect behavior but there are other components affecting behavior as well. If one's beliefs are not fully internalized, incongruence occurs between those beliefs and the behaviors a person takes (Chatzidakis, Hibbert, \& Smith, 2007).

Wilson's (2007) studies show that belief is the best predictor of intent to act. Beliefs can be influenced by factors such as attitude, feelings, experiences, and social aspects. This means that all of these factors must be taken into consideration when trying to understand what consumers believe about green marketing, its importance, and how they may act on these beliefs. Sukato and Barry (2009) have shown that personal beliefs, the influence of others and attitudes are good predictors of purchase intentions in the cosmetic industry.

Stall-Meadows, Swiney, and Davey (2009) have extended the TRA to include persuading advertising messages as one of the influences on consumer beliefs and attitudes in the purchase of eco-friendly apparel. They recommend that businesses strongly communicate their commitment to corporate social responsibility to encourage consumers to purchase green products from them. Consumers are even willing to pay a premium to buy these products from them. Ng and Palidono (2009) found that the TRA is more applicable to consumering decisions under their volition, going green being one such decision.

Whaid, Rahbar, and Shyan (2011) extended the TRA model to include knowledge and concern about environmental issues, and knowledge about green products as factors determining enthusiasm to volunteer for environment related activities. Chen and Chai (2010) demonstrated that individuals who feel a strong moral obligation to protect the environment, a variable similar to the belief component of TRA, are more likely to engage in green consumption activities. The strong support in the literature for the TRA leads us to the following hypothesis.

H1: Attitude toward green consumption and the subjective norms concerning this behavior influence a person's intention to purchase green as the TRA model predicts. Attitudes toward green consumption will in turn be determined by an individual's beliefs that green consumption results in desirable outcomes and the importance of these outcomes to them. Subjective norms will be determined by what significant others in 
an individual's life think about green consumption and their motivation to comply with the will of these referent others.

\section{METHODS}

This exploratory study aims to better understand and possibly predict consumers' green consumption behavior. To this end a survey was developed and administered to a sample of 302 undergraduate business school students and was later extended to include a second sample consisting of 202 non-student respondents. Each respondent came from the Northeastern coastal region of the United States. The rationale for gathering similar data from a non-student sample stems from the authors concerns that the student sample may be an over-representation of a younger age demographic. The inclusion of a sizable number of non-student respondents adds credibility and support to this study's findings.

Subjective norms were estimated to the extent to which referent others think an individual should engage in green consumption as well as the importance s/he attaches to those opinions. The survey (Appendix A) consists of six belief statements followed by six corresponding evaluation statements, which are used together to determine respondents' attitudes towards the behavior (purchasing and consuming green products). Following are six normative belief statements with corresponding motivation to comply measures for three referent-others (family, friends, and neighbors). These are used to estimate respondents' subjective norms and their perceptions of the social pressure to purchase/consume green products. Respondents in both the student and non-student samples were instructed to indicate their level of agreement/ disagreement with these statements using a 5-point Likert scale.

Furthermore, respondents were asked to indicate: (a) their intentions to purchase green products and b) their current green consumption choices. With the goal of understanding green consumption behavior, the first step of our analysis examines the extent to which respondents' intentions translate into actual behavior. Factor analysis usefully reduces the data to a manageable level while eliminating noise in the data set. The four intention statements are subjected to a principles component factor analysis with varimax rotation (eigen value $=1$ ). Two factors labeled as intent 1 and intent 2 emerge from this analysis (Table 1 available from authors). Factor loadings of less than 0.4 are suppressed. Almost every respondent checked off at least one green consumption activity from the list at the end of the survey.

\section{RESULTS AND DISCUSSION}

The student sample shows significant correlations between intentions and behavior of 0.1 and 0.3 . Only the second factor is significant with a correlation coefficient of 0.3 as Table 3 indicates (available from authors). Though these correlations are not high in absolute terms they are statistically significant $(\mathrm{p}<0.05)$ and validate the TRA model in application to green consumption behavior.

According to the TRA, a person's intention to purchase green products is determined by his/her attitude toward green consumption and by his/her subjective norm concerning this behavior. Since green consumption intentions are found to significantly correlate with the person's actual purchasing behavior, consideration of the attitudinal and normative antecedents of this intention are investigated next.

First, a closer look is taken at the contribution of each belief by multiplying the belief and evaluation scores $(\mathrm{b} x \mathrm{e})$ for each of the six attributes and then correlating the result with the overall attitude towards the behavior measure. As reported in Figure 2 (available from authors), all six BE pairs in the student sample correlate significantly with Attitude, with belief statement 3 "Consuming green products requires commitment and effort" exhibiting the highest correlation, and belief statement 4 "Consuming green products is an inconvenience" exhibiting the lowest.

The correlation results between $\mathrm{B} \times \mathrm{E}$ pairs and overall attitude towards the behavior measure for the nonstudent segment of the survey appear in Figure 2 (available from authors). Again, all six BE pairs significantly correlate with attitude. For the non-student sample, belief statement 1 "Consuming green products will reduce environmental damage" exhibits the highest correlation, and belief statement 4 "consuming green products is an inconvenience "again exhibits the lowest correlation. 
Similarly, the contributions of the normative belief statements are analyzed by multiplying them with the corresponding motivation to comply scores and then correlated to the overall subjective norm measure. Analysis of results and subsequent examination of the correlation of overall subjective norm measure and the multiplication scores (NB x MC) indicate significantly high Pearson correlation coefficients for all six NB x MC pairs across both samples (Figure 3 available from authors). The non-student sample, mostly older and upper middle class respondents are less influenced by subjective norms and motivation to comply. This group demonstrates higher correlations between B x E pairs and attitudes. This suggests that their attitudes are more carefully formed than the younger student sample. This is to be expected as the non-student sample has had more life experiences.

Finally, Figure 4 (available from authors) demonstrates that both the attitude and SN measures correlate to the intention measures (intent1 and intent2) positively and significantly. An examination of these correlation coefficients for the non-student sample denotes stronger correlation between Intention and Attitude than between Intention and Subjective Norms (where correlation was significant only with Intent2). Apparently, younger people are more influenced by what others think about an issue than are older folks.

Future research could examine this discrepancy using Social Dilemma Theory (SDT). SDT explores situations in which collective interests are at odds with private interests, or where the rational purely economic behavior of an individual leads to suboptimal outcomes from the collective standpoint (Dawes, 2008; Kollock, 1998).

Such dilemmas create interesting situations for understanding green marketing and consumption behaviors. Consumers are not necessarily demanding green products, but rather the businesses are leading the green movement. An article by J. Walker Smith (2007) states that the marketing professionals must do more than change attitudes, they must try and change behavior. Smith (2007) challenges the traditional marketing assumption based on the Theory of Reasoned Action, saying that behaviors must change so people are acting green whether or not they think green.

Several marketing researchers strive to identify distinct segments of green consumers through the use of demographic, psychographic, and behavioral variables. A number of these studies examine age as a pertinent predictor of green consumption, some of which suggest no significant correlation between the two (Kinnear, Taylor, \& Ahmed, 1974). Others - such as Roberts (1996) and Samdahl and Robertson (1989) - propose a significant and positive correlation, whereas others - such as Van Liere and Dunlap (1981) and Zimmer, Strafford, and Strafford (1994) - find a significant negative correlation between age and environmental awareness and behavior.

Other researchers' findings point to a positive relationship between the demographic/ psychographic variable education level and environmental attitudes. Consumers with higher levels of education display greater concern for the environment and are more likely to consume in favor of the environment (Granzin \& Olsen, 1991; Roberts, 1996). Furthermore, other researchers suggest that income positively correlates with environmental awareness and concern (Berkowitz \& Lutterman, 1968). Consumers with middle to high incomes are more likely to engage in pro-environmental consumption.

This study's results show some interesting differences in beliefs between the student and adult non-student samples. For the student sample, the belief that "consuming green products requires commitment and effort" exhibits the greatest correlation with attitude. For this generally younger respondent group, convenience is very important. If organizations are to make green products more readily available and the process of buying environmentally-friendly products less demanding, these younger consumers may be more likely to engage in proenvironmental behavior.

As for the non-student sample, which consists mainly of older professionals, the belief statement with the greatest correlation to attitudes was that "consuming green products will reduce environmental damage". This perspective illustrates greater awareness and a deeper commitment among this older, more informed/educated group towards ecological issues and concerns. Furthermore, for this non-student sample, attitude correlates more strongly with intention than social norms. This result is important in confirming the deep personal initiative and commitment among these respondents to behave in environmentally-conscious ways. Peer pressure to be green is less pronounced among the older adult, non-student sample. 


\section{LIMITATIONS}

Although the survey requests some demographic reporting, it did not give us complete demographic reports. In hindsight, the design did not identify heavy engagers versus non-engagers. Self reporting can be suspect, leaving the question whether people are honest when reporting on themselves. Multiple measures might have been useful.

Furthermore, the present study measures intentions to go green and not the actual purchases of green products. Future research may address this limitation by linking intentions with behavior to test Ajzen's (1991) TPB. Further research could also look into how corporations can build effective promotional campaigns that convey their green position and their sincerity of purpose to their audience. Paco, Raposo, and Fiho (2009) usefully identify demographic and psychographic variables which can be linked to the TPB. In a similar effort, this study is extendable to include other mediating/moderating demographic (such as income, education, and ethnicity), and psychographic variables, such as personality, lifestyle, knowledge, and involvement.

\section{MANAGERIAL IMPLICATIONS AND APPLICATIONS}

Consumers do want green products and are willing to pay a little bit more for them. Businesses have to make sure they identify green products through proper packaging and labeling and place them in easy to find locations. Eco-labels are recognized as a way to increase sales as they differentiate products, demonstrate a company's accountability, and yield more green consumer options (Horne, 2009). The green consumer market is segmentable through demographic variables just as any other market. Green consumers are likely to enjoy higher income and education levels than the average consumer.

If a majority of businesses follow the "green path", expensive environmental regulations from the government may become unnecessary in the future. Businesses can easily demonstrate their awareness of Corporate Social Responsibility (CSR) by catering to green consumers and improving their corporate image, as successfully demonstrated by the Brazilian oil giant Petrobras (Azevedo, 2009).

\section{CONCLUSION}

Green marketing is considered one of the major trends in modern business (Kassaye, 2001; McDaniel \& Rylander, 1993; Pujari \& Wright, 1996). When consumer consumption increases, the economy grows rapidly as seen in past decades, worldwide. Building long-term profitable customer relationships and stimulating customer satisfaction are some of the primary objectives of an organization as they strive to sustain their businesses in the competitive business world. As social and political pressures have been on the increase, many firms embraced green marketing strategies. These environmental issues can be a source of competitive advantage.

The final corporate issue revolves around the question of growth. Businesses want to expand their markets and profitability, but can growth occur in an environmentally sustainable fashion (van Marrewijk 2003)? Organizational strategy, government policy, and individuals' behavior are the keys. Marketers, consumers and government each and together play a role in the evolution of green consumerism and the behaviors around it.

\section{AUTHOR INFORMATION}

Linda Jane Coleman is a Professor of Marketing in the Marketing and Decision Sciences Department at Salem State University in Salem, Massachusetts. She earned a Bachelor of Science degree in Business Administration from West Virginia Wesleyan College, a Master of Science degree in Management from Virginia Commonwealth University, and Postgraduate work in the area of Marketing and Organizational Behavior at the University of Baltimore and the University of Maryland. She has published in a variety of Journals and Proceedings and has presented papers nationally and internationally. Her research interests include Green Marketing, Social Marketing, Human Resource Development, and International Marketing. 
Nisreen Bahnan, Ph.D. is Associate Professor of Marketing at Salem State University, Bertolon School of Business in Salem, Massachusetts. She has earned her Ph.D. in Business Studies from Temple University in Philadelphia, Pennsylvania. She is presently teaching Principles of Marketing, Marketing Management and Consumer Behavior. She has presented at conferences and published articles in the fields of Services Marketing and Consumer Behavior.

Mayuresh Kelkar, Ph.D. is an Assistant Professor of Marketing in the Bertolon School of Business at the Salem State University. He received a Ph.D. in Marketing from the University of Arkansas Fayetteville. Articles authored or coauthored by Dr. Kelkar have appeared in the Journal of Marketing Channels, Journal of International Marketing and Exporting, Journal of Promotion Management, Journal of Marketing for Higher Education, and the Journal of Professional Services Marketing.

Nicole Curry, MSW is a recent graduate of Salem State University, where she earned her Masters of Social Work. She earned her undergraduate degree at Endicott College in Beverly, Massachusetts, where she studied Human Services and Education. She began working with Professor Coleman as a graduate assistant and has continued to collaborate on projects. Ms. Curry is currently employed with Thom Mystic Valley Early Intervention.

\section{REFERENCES}

1. Ajzen, I. (1991). The Theory of Planned Behavior. Organizational Behavior and Human Decision Processes, 50 (2), 179-211.

2. Ajzen, I. \& Fishbein, M. (1980). Understanding Attitudes and Predicting Social Behavior. Englewood Cliffs, NJ: Prentice Hall.

3. Azevedo, J.B.G. (2009). The Greening of Petrobras. Harvard Business Review, 87 (3), $43-47$.

4. Berkowitz, L. \& Lutterman K. (1968).The Traditional Socially Responsible Personality. Public Opinion Quarterly, 32 (2), 169-185.

5. $\quad$ Brandt, D. A (2007). World Gone Green. Industrial Engineer, 39 (9), 28-33.

6. Ceccucci, W., Peslak, A. \& Sendall, P. (2010). An Empirical Study of Behavioral Factors Influencing Text Messaging Intention. Journal of Information Technology Management, 21 (1), 1042-1319.

7. Chan, Y,K.R. (2001). Determinants of Chinese Consumers' Green Purchase Behavior, Psychology \& Marketing, 18 (4), 389-413

8. Chassin, I., Presson C. C., Bensenburg M., Corty F., Olshavsky R.W., \& Sherman S. J. (1981). Predicting Adolescents' Intentions to Smoke Cigarettes. Journal of Health Social Behavior, 22 (December), 445-455.

9. Chatzidakis, A., Hibbert, S., \& Smith, A. (2007), Why People Don't Take their Concerns about Fair Trade to the Supermarket: The Role of Neutralisation. Journal of Business Ethics, 74 (1), 89-100

10. Chen, T.B. \& Chai, T. L. (2010). Attitude Towards the Environment and Green Products: Consumers' Perspective, Management Science and Engineering, 4(2), 27-39.

11. Chen, T.L. \& Chen, T.J. (2006). Examination of Attitudes Towards Teaching Online Courses Based on the Theory of Reasoned Action of University Faculty in Taiwan. Journal of Education Technology, 37 (5), 683-693.

12. Dawes, R. (2008). Social Dilemmas. Annual Review of Psychology, 31, 169-193.

13. D'Souza, C., Taghian, M., \& Khosla, R. (2007). Examination of Environmental Beliefs and its Impact on the Influence of Price, Quality and Demographic Characteristics with Respect to Green Purchase Intention. Journal of Targeting, Measurement, \& Analysis for Marketing, 15 (2), 69-78.

14. D'Souza, C., Taghian, M., Lamb, P., \& Peretiatk, R. (2007).Green Decisions: Demographics and Consumer Understanding of Environmental Labels. International Journal of Consumer Studies, 31 (4), 371-376.

15. Fishbein, M. (1967). Attitude and the Prediction of Behavior. In Fishbein M. (Ed.), Readings in Attitude Theory and Measurement. New York, NY: John Wiley.

16. Fishbein, M. (1980). A Theory of Reasoned Action: Some Applications and Implications. In Howe H. E. and Page M. M. (Eds.), Nebraska Symposium on Motivation. Lincoln, NE: University of Nebraska Press.

17. Fishbein, M. (2008). A Reasoned Action Approach to Health Promotion. Medical Decision Making, 28 (6), 834-844.

18. Fishbein, M. \& Ajzen, I. (1975). Belief, Attitude, Intention, and Behavior: An Introduction to Theory and Research. Reading, MA: Addison-Wesley. 
19. Fishbein, M., Middlestadt, S. E., \& Hitchcock, P. J. (1991). Using Information to Change Sexually Transmitted Disease-Related Behaviors: An Analysis Based on the Theory of Reasoned Action. In Wasserheit J. N., Aral S. O., Holmes K. K. and Hitchcock P. J., (Ed), Research Issues in Human Behavior and Sexually Transmitted Diseases in the AIDS Era (pp.61-78). Washington, DC: American Society for Microbiology,.

20. Friedman, T. (2008). Hot, Flat, and Crowded: Why we Need a Green Revolution and How it Can Renew America. New York, NY: Farrar, Straus, and Giroux.

21. Garman, G., Arnett, D., \& Mauk, E. (2008). Breast Feeding Intentions Among Low Income Pregnant and Lactating Women. American Journal of Health Behavior, 32 (2), 125-136

22. Golan, G.J. \& Banning, S.A. (2008). Exploring a Link between the Third-Person Effect and the Theory of Reasoned Action: Beneficial Ads and Social Expectations. American Behavior Science, 52 (2), 208-224.

23. Granzin, K. \& Olsen J. (1991). Characterizing Participants in Activities Protecting the Environment: A Focus on Donating, Recycling, and Conservation Behaviors. Journal of Public Policy and Marketing, 10 (2), 1-27.

24. Hine, D.W. \& Gifford, R. (1991). Fear Appeals, Individual Differences, and Environmental Concerns. Journal of Environmental Education, 23 (11), 36-39.

25. Horne, R.E. (2009). Limits to Labels: The Role of Eco-labels in the Assessment of Product Sustainability and Routes to Sustainable Consumption. International Journal of Consumer Studies, 33 (2), 175-182.

26. Hounshell, P.B. \& Liggett, L. (1973). Assessing the Effectiveness of Environmental Education. Journal of Environmental Education, 5 (2), 28-30.

27. Kassaye, W. W. (2001). Green dilemma. Marketing Intelligence \& Planning, 19 (6), 444-55.

28. Kinnear, T., Taylor J., \& Ahmed S. (1974). Ecologically Concerned Consumers: Who are They? Journal of Marketing, 38 (2), 20-24.

29. Kollock, P. (1998). Social Dilemmas: The Anatomy of Cooperation. Annual Review Sociology, 24, 183214.

30. McDaniel, S. \& Rylander, D. (1993). Strategic green marketing. Journal of Consumer Marketing, 10, 4-10.

31. Mintzer, R. (2008). Taking a Green Initiative. The Washington Post. Retrieved March 3. 2008 from http://www.washington post.com/

32. Ng, S. \& Paladino, A .(2009). Examining the Influence of Intentions to Purchase Green Mobile Phones Among Young Consumers: An Empirical Analysis, Australian and New Zealand Marketing Academy, Melbourne Conference Proceedings, p. 1-8.

33. Paco, A.M.F., Raposo, M.LB, \& Filho, L.W. (2009). Identifying the Green Consumer: A Segmentation Study. Journal of Targeting, Measurement, and Analysis for Marketing, 17 (1), 17-25.

34. Pfanner, E. (2007). Big Consumer Products Maker Proclaims the 'Green' Virtues of Using Dishwashers. The New York Times. Retrieved February 3, 2008 from http://www.nytimes.com/

35. Prescott, M. \& Taylor, M. (2008). Every Citizen a Carbon Trader? World Policy Journal, 25 (1), $19-21$.

36. Pujari, D. \& Wright, G. (1996). Developing environmentally-conscious product strategy: A qualitative study of selected companies in Britain and Germany. Marketing Intelligence and Planning, 14(1), 19-28.

37. Roberts, J. (1996). Green Consumers in the 1990s: Profile and Implications for Advertising. Journal of Business Research, 36 (3): 217-232.

38. Ross, L., Kohler, C.L., Grimely, D., \& Anderson-Lewis, C. (2007). The Theory of Reasoned Action and Intention to Seek Cancer Information. American Journal of Health Behavior, 31 (2), 123-134.

39. Samdahl, D. \& Robertson R. (1989). Social Antecedents of Environmental Concern: Specification and Test of the Model. Environmental Behavior, 21 (1), 57-81.

40. Schlegel, R. P., Crawford C.A., \& Sanborn M.D. (1977). Correspondence and Mediation Properties of the Fishbein Model: An Application to Adolescent Alcohol Use. Journal of Experimental Social Psychology, 13 (5), 421-430.

41. Shaharudin, M.R., Pani, J.J., Mansor, S.W. \& Elias, S.J. (2010). Factors Affecting Purchase Intention of Organic Food in Malaysia's Kedah State. Cross-Cultural Communication 6 (2), 105-116

42. Sheu, T.S. (2006). A Comparison of the Theory of Reasoned Action with the Theory of Planned Behavior in Predicting Higher Education Students' Behavioral Intentions. Proceedings of the $7^{\text {th }}$ Asia Pacific Industrial Engineering and Management Systems Conference.

43. Smith, J. Walker. (2007). Green is Not an Attitude. Marketing Management, 52. Retrieved June 11, 2008 from Business Source Premier Database. 
44. Stall-Meadows. C., Swiney, J., \& Davey A. (2009). Green Jeans: A Qualitative Study of Consumer Preferences for Green Apparel, International Textile and Apparel Association, Inc. Proceedings\#66, Bellevue, Washington, USA.

45. Straughan, R. \& Roberts, J. (1999). Environmental Segmentation Alternatives: A Look at Green Consumer Behavior in the New Millennium. Journal of Consumer Marketing, 16 (6): 531-575.

46. Sukato, N. \& Barry, E., (2009). A Model of Male Consumer Behavior in Buying Skin Care Products in Thailand, ABAC Journal, 29 (1), 39-52.

47. Tanner, C. \& Kast, S.W. (2003). Promoting Sustainable Consumption: Determinants of Green Purchases by Swiss Consumers, Psychology \& Marketing, 20(10), 883-902.

48. Wahid, A.N., Rahbar, E., \& Shyan, S. T. (2011). Factors Influencing the Green Purchase Behavior of Penang Environmental Volunteers, International Business Management, 5(1), 38-49.

49. Wilson, E. (2007). A World Consumed by Guilt. The New York Times. Retrieved March 2, 2008 from http://www.nytimes.com,

50. Van Liere, K. \& Dunlap R. (1981). Environmental Concern: Does it make a Difference How its Measured? Environmental Behavior, 13, 651-676.

51. Van Marrewijk, M. (2003). "Concepts and Definitions of CSR and Corporate Sustainability: Between Agency and Communion,” Journal of Business Ethics, 44(2-3), 95-105.

52. Zimmer, M., Strafford T., \& Strafford M. (1994). Green Issues: Dimensions of Environmental Concern. Journal of Business Research, 30 (1), 63-74. 